\title{
TECHNICAL ASPECTS IN THE GEOGRAPHY PERCEPTION PROCESS
}

\author{
David A. Eastwood \\ Department of Environmental Studies \\ University of Ulster
}

\section{INTRODUCTION}

The purpose of this paper is twofold:

1.- To briefly examine the rationale behind perception studies in geography and to assess the need for, and the current sucess of, perception and behavioural studies in geography.

2.- At greater length, to examine the methodological possibilities and technical difficulties involved in geographical perception research.

Definition: Perception is an extremely complex concept. For example, The International Encyclopedia of the Social Sciences devotes more than fifty pages to discussing its meaning. However, geographic research interest in perception studies has focussed almost entirely on the relatively narrow field of social perception. Although still sufficiently complex to require eight pages of discussion in the International Encyclopedia, social perception is essentially concerned with the effects of social and cultural factors on our cognitive structuring of our physical and social environment. Social perception therefore depends on more than the objective stimulus present and the biological capabilities of our sense organs. It also varies with the individual's past experiences and present attitudes reflecting values, needs, memories, moods, social circumstances and expectations. Consequently, as Saarinen (1976) notes:

"The major problem in studying people's perception is that of measurement, since people often have difficulty articulating the conscious or unconscious feelings, attitudes, or ideas associated with perception. In many cases perception must be inferred, from behaviour or from other indirect sources". 
Put simply therefore, the fundamental problem of perception studies is to objectively quantify a subjective world.

\section{THE RATIONALE AND CURRENT POSITION OF GEOGRAPHICAL PERCEPTION STUDIES}

The empirisism which accompanied the quantitative revolution in geography in the $1960^{\prime}$ s generated two associated demands:

1.- the need for measurement, and the production of high quality, objective data,

2.- the need to analyse not only patterns, but also the processes underlying these patterns.

Only through a combination of these could predictive studies be possible.

Processes underlying patterns in human geography inevitably reflect the human decision making processes, in turn reflecting human behaviour patterns. The need for behavioural geography to objectively analyse subjective decision making and behaviour was therefore obvious.

Perception forms an important part of any decision making process. In Decision Making, Edwards and Tversky (1967) analyse decisions in terms of four variables, each operating at both objective and subjective levels. These are:

\section{OBJECTIVE LEVEL}

1 INFORMATION

(The factual basis for the decision)

2 VALUE

(What is wanted from the decision)

3 RISK

(The probability of getting it )

4 RATIONAL CALCULATING MAN

(The person making the decision -

in this case an 'objective' person)

\section{SUBJECTIVE LEVEL}

\section{PERCEPTION}

(The subective interpretation of the information)

UTILITY

(Subjective value)

UNCERTAINTY

(Subjective risk)

PERSONALITY

(The basis of subjectivity)

In an abstract, objective world therefore, any decision can be understood (and, more importantly, predicted) as the rationally calculated outcome of (1) available information, (2) what value the decision can yield, (3) the probabilities of successfully achieving this value. However, In the real world, these variables only operate and interact subjectively, dependent on individual's personality (with personality itself a dependent function of genetics and socio-cultural environment). Prediction, other than prediction based on historically revealed preference, is 
therefore virtually impossible without individual subjective analysis (and is difficult, if not impossible, even then).

Subjective analysis is difficult even at the individual level, and even more difficult to aggregate into large scale, or group studies. These difficulties will be more fully elaborated later in this paper. Nonetheless, the alternative to not studying subjectively is to pretend that the decision making processes and their resultant patterns in the real wold operate objectively, which is demonstably not the case.

Take for example the data below (fig. 1) derived from 8 annual geography practicals examining stereotypes in the University of Ulster in which first year students were given a list of 17 adjectives and asked to select the 3 they thought most apprpriate to describe given nationalities. The uniformity of the resultant pattern is self evident. Clearly the accidental probability of the same 3 adjectives being chosen each year from 17, as in the case of the Turks, is astronomical. This is not to say that the adjectives are true, or that such stereotypes will predict behaviour patterns, or even that we can say from where these stereotypes evolve - after all few Ulster students have read much about the Turks, let alone met one - yet a perceptual pattern nonetheless clearly and intriguingly exists and cannot simply be ignored.

Throughout the late 1960's and early 1970's the establishment of geographical perceptual patterns at the group level proved irrisistably attractive to behavioural geographers, as can be seen in the proliferation of perception studies during this time. However, this focus on perceptual pattern was in many ways counterproductive. The establishment of pattern, as illustrated with respect to stereotypes above, tells us nothing about the decision making processes to which such perceptions contribute. Inevitably therefore, the practical applications of such studies,intrisically intriguing though they may be, remain strictly limited in terms of prediction or planning.

Perception studies indisputably form a valuable tool in the understanding of real world decisions. Nonetheless, in my opinion, they are best seen as exactly this a contributory variable in decision making - rather than as an independent field of studies in themselves. Otherwise, they will continue to be an intriguing abstraction, rather than as a practical tool in the understanding of real world processes.

Unfortunately, throughout the early 1970's, geographical perception studies became progressively more divorced from any real world decision making context; focussing instead on increasing levels of abstraction and pattern. The burgeoning proliferation of,for example, mental map studies at this time, with little or no attention paid to the applicability of such studies, or of their contribution to any wider decision making process, illustrates this point. Hardly surprising therefore, that the volume of geographical perception studies began to decline in the mid 1970 's, a decline which has continued since. 

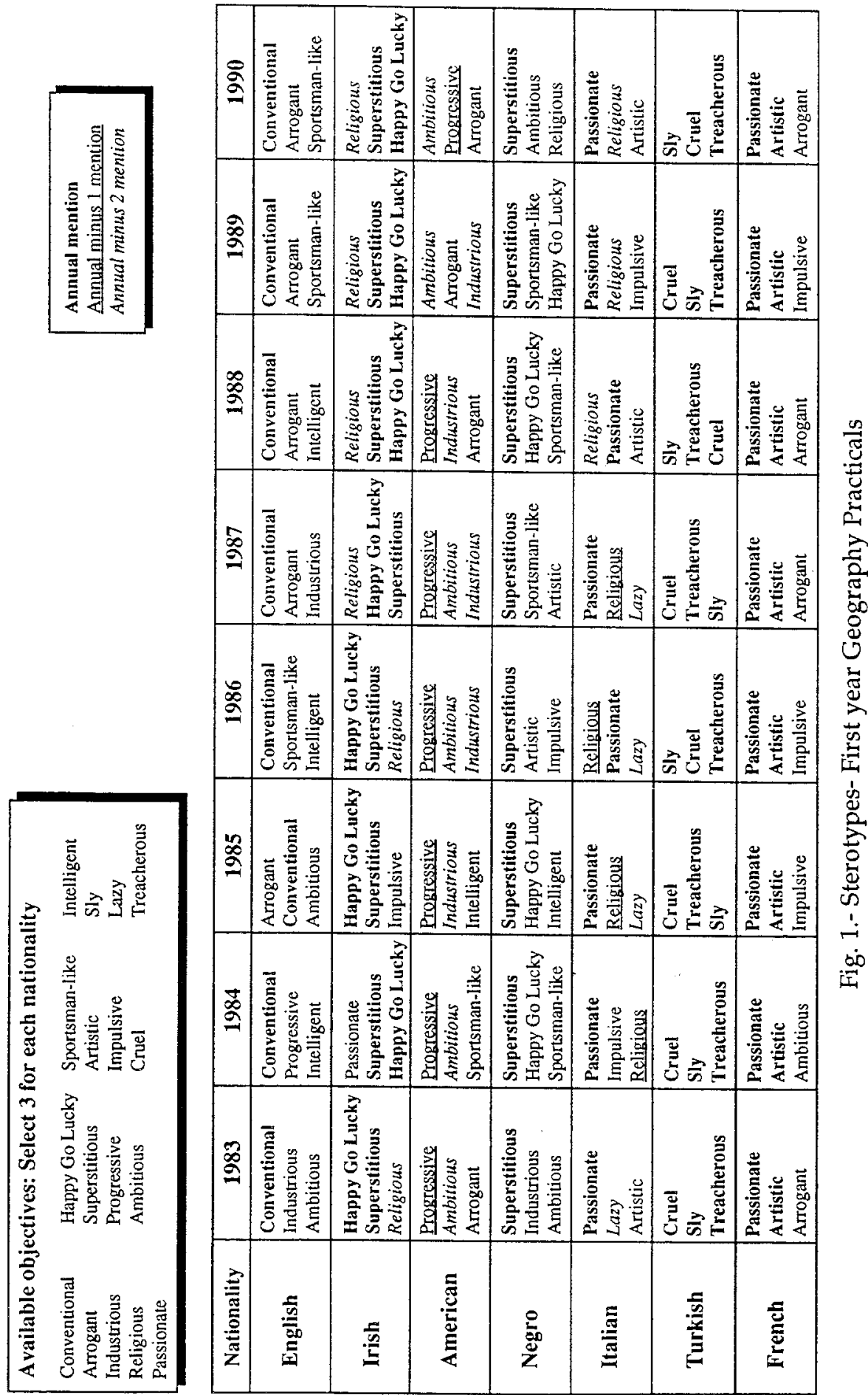
Yet, viewed in the context of decision making, perception remains an essential variable, but one which, I feel, should never be wholly divorced from personality study. It seems to me to be pointless to focuss attention exclusively on a more dependent variable (perception) to the total exclusion of a more independent variable (personality), yet too often this has been the case.

Significantly, during the 1980's and 1990's, in environmental perception studies emanating from psychology departments, as opposed to geography departments, this role has been reversed, with attention focussing firstly on personality and only secondly on perception. Also, significantly, the quantity of environmental perception studies from within psychology has continued to increase, paralleling the decline from within geography.

Nonetheless, despite these reservations about the context and the focus of geographical perception studies over the last 20 years, decisions continue to be made, processes continue to happen and patterns to form. In turn, the empirical demands for high quality, accurate data continues to grow from within contemporary geography and this continues to emphasise the need for real world subjective investigation. However, the methodological and technical difficulties involved in generating appropriate data remain considerable.

\section{DATA COLLECTION AND MEASURING TECHNIQUES}

The collection and interpretation of high quality and reliable data is fraught with problems even in an objective world, as the many volumes of textbooks devoted to questionnaire design, sampling and statistical analysis confirm. But it is even more difficult in a subjective world of, for example perceptions and attitudes, not so open to direct observation or confirmation and therefore heavily dependent on inference, and where, as Saarinen (1976) has stressed : sources"

"in many cases perception must be inferred from behaviour and from indirect

Three broad types of research techniques account for virtually all behavioural and perception research :

1.- Direct Observation Techniques

2.- Direct Self Report Techniques (e.g. questionnaire surveys )

3.- Indirect Self Report Techniques (e.g. projective testing )

The advantages, disadvantages and limitations of each of these techniques in the context of geographical perception research will each now be briefly reviewed in turn. 


\section{Direct Obsevation Techniques}

Sometimes referred to as the ecological approach, and also widely used within psychology, anthropology and sociology (Craik, 1970), direct observational techniques rely on the direct observation and recording of subjects in selected environments with no participant contacts between the subjects and the observing researchers. Observational techniques therefore have the advantage of avoiding the standard criticism of all self report techniques that participant contact between subjects and researchers, such as the contacts involved in asking questions, creates an artificial behavioural environment, and therefore inevitably contaminates the real behaviour patterns of the subjects concerned.

However, although absence of participant contact does have this particular advantage, it also has the severe disadvantage that research conclusions can therefore only be drawn from direct observation by inference, and can never be wholly substantiated. Consider, for example,the observations made by Sommer (1969) on the ecology of classroom participation (fig. 2).

\section{INSTRUCTOR}

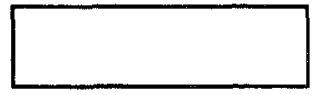

\begin{tabular}{|l|l|l|}
\hline $57 \%$ & $61 \%$ & $57 \%$ \\
\hline \multicolumn{3}{|c|}{} \\
\hline $37 \%$ & $54 \%$ & $37 \%$ \\
\hline \multicolumn{3}{|c|}{} \\
\hline $41 \%$ & $51 \%$ & $41 \%$ \\
\hline $31 \%$ & $48 \%$ & $31 \%$ \\
\hline
\end{tabular}

Figure 2.- Ecology of Participation in Strainght - Row Classrooms

Clearly rates of participation amongst students, for example in asking questions or direct eye to eye contact with the teacher, are higher amongst those students sitting at the front of the class. But what conclusions can be infered from this? Is it that the most interested students in any class always sit at the front? Or is it that, if finding themselves sitting at the front, all students tend to show more interest and to participate more? Or is it a little of both these logical possibilities?

The inability to generate wholly substantiated conclusions severely restricts the use of direct observational techniques in perception research. Nonetheless 
observational techniques can still make extremely valuable contributions in perception research, notably in the early exploratory stages of research projects, and especially by highlighting lines of potential investigation through inference, which can subsequently be further pursued at greater depth by other more specific self reporting techniques. Kevin Lynch's (1960) "Image of the City" research, for example began with exploratory direct observation techniques recording subject behaviour walking through cities, prior to employing a number of self reporting techniques to analyse the subject perceptions underlying this behaviour in greater detail.

\section{Direct Self Report Techniques}

As the current plethora of geographical survey methods and statistical analysis textbooks confirm, Direct Self Report Techniques (such as participant observation or questionnaire techniques) are by far the most common techniques for data gathering used throughout the social sciences. Certainly they need no elaboration here. However, it is necessary to sound one important note of caution about their application, not only in terms of perception studies, but in terms of geography as a whole.

Aided by the development of computer package statistical analysis programs, such as SPSS, quantitative geography currently exhibits a particularly unhealthy tendency to be obsessed with data analysis, where data are crunched to the Nth degree of resolution, while at the same time transparently neglecting interest either in how that data was originally collected, or in how accurate that data might be. Data gathering has become distressingly - under regarded relative to data analysis, and this despite the fact that the 'garbage in - garbage out' adage ostensibly remains the number one premise of all data analysts.

Questionnaire techniques have become especially abused. Obviously the real world, rather than laboratory, situation within which the social sciences must conduct research means that pure scientific methodology is usually impractical and frequently impossible - repeat testing to validate results is an obvious case in point it is usually impossible to gather the same subjects together either spatially for repeat testing or, even if this is possible, then the time dimension has changed. However, even in those rare situations where some repeat testing is attempted some fixed-sample public opinion polls for example - poor question design can still lead to substantially misleading results.

The abject failure, despite the massive investment in time and manpower devoted to them, of the national opinion polls to predict the results of the last British general election are a classical example of the dangers of uncritical analysis of questionnaire gathered data. How much more unreliable however is data gathered less professionally, or on a smaller scale, or not on a repeat experiment basis.

One further example will illustrate this personal concern with data reliability some results from some of my own research on patterns of migration in the Venezuelan Andes. In this I was looking at a number of migrant and non-migrant 
personality characteristics and one of the tests I was using was a standard Eysenck EPI questionnaire to investigate levels of introversion / extraversion and neuroticism / stability. The EPI questionnaire uses direct questions - for example, "do you like fiestas?" - and is therefore theoretically the technically simplest form of question available. The EPI also demands a simple yes / no response. There is no 'don't know', or scaled response. Again therefore theoretically it is the simplest form of questionnaire design available.

However, unlike probably $99 \%$ of questionnaires used in geographical research, the EPI contains a built in lie check where some questions are repeated in a marginally different format in order to check the consistency, and hence the reliability, of the respondent. 9 of the 57 questions are repeated in this way and, normally 1-2 of the 9 repeated questions not generating the same answer both times means that the respondent is classed as unreliable and the questionnaire should be therefore discarded.

In the case of the results given in Figure 3, the conventional 1-2 unreliability level was relaxed to 4 - i. e. respondents were only discarded if they registered 5 or more lies in 9 repeat questions. Nonetheles, even at this almost ridiculously relaxed level, $46 \%$ of non-migrants and $62 \%$ of migrants failed the lie test. (Incidentally the EPI is commercially produced in Spanish translation and the tests were administered not by me, but by native speakers, so in this case there was no possibility of linguistically induced errors in these results).

\begin{tabular}{|l|c|c|}
\hline & Migrant & Non-Migrant \\
\hline Number of lie test scores 0-9 (Ni) & 180 & 205 \\
\hline Number of lie test scores 0-4 (N2) & 68 & 110 \\
\hline $\begin{array}{c}\text { Percent valid test (-- } \mathrm{Ni} \text { 100)-Reliability } \\
\mathrm{N} 2\end{array}$ & $37.8 \%$ & $53.7 \%$ \\
\hline
\end{tabular}

Figure 3.- Lie Test Reliability Scores

If over $50 \%$ of respondents are unreliable in a questionnaire where the design (direct questions) and the response (yes / no answers) are the theoretically simplest techniques available in questionnaire research one shudders to think of the reliability of much of the geographical research where neither repeat testing, nor even the basic precaution of a simple lie test is included in the data gathering irrespective of the sophisticated statistical analysis to which the answers may subsequently be submitted. 


\section{Indirect Self Report Techniques}

As noted in the Saarinen (1976) quotation at the beginning of this paper, because subjects "often have difficulty articulating the conscious or unconscious feelings, attitudes, or ideas associated with perception "therefore," in many cases perception must be inferred ..... from other indirect sources". The indirect sources which have been most commonly employed to investigate such subjective attitudes are usually referred to as Projective Techniques, and a number of different projective techniques have been used in geographical perception research.

Lindzey (1961) defines a projective technique as: "an instrument that is considered especially sensitive to covert or unconscious aspects of behaviour, it permits or encourages a wide variety of subject responses, is highly multidimensional, and it evokes unusually rich and profuse response data with a minimum of subject awareness concerning the purpose of the test". He adds further that "the stimulus material presented by the projective test is ambiguous, interpreters of the test depend upon holistic analysis, the test evokes fantasy responses, and there are no correct or incorrect responses to the test".

Put simply, therefore, projective testing means offering some form of cue or other stimulus to the imagination of a subject and then to analyse the results of that imagination.

Based on differences in the type of cue or stimulus used, Lindzey classifies 5 different types of projective technique:

1.- Association Techniques (e. g. word association, Rorschach etc.)

2.- Construction Techniques ( e. g. thematic apperception tests)

3.- Completion Techniques (e. g. sentence completion tests)

4.- Choice or Ordering Techniques (e.g. semantic differential tests)

5.- Expressive Techniques (e. g. world map drawings)

The remainder of this section will very briefly examine the pros and cons of each of these techniques in so far as they have been used in geographical perception research.

1.- Association Techniques - these depend on the immediate response of the subect to the stimulus (which is usually a verbal stimulus ). Association testing was used in some early geographical studies of perceptions of countries - Haddon (1960) for example asked British subjects to describe the images which came immediately to mind when thinking of U.S.A., France, Australia, etc., and Cole (1970) did similar work on Cariocas - but, used in this way, association techniques are very unspecific 
and are therefore difficult to quantify and, hence, to compare. This type of stereotyping work has therefore gravitated rapidly towards choice / ordering techniques \{Fig. 4.\}, which have proved to be much more precise and to facilitate easy comparison.

2.- Construction Techniques - require subjects to go beyond simple association to stimulus and to create, or construct, a more elaborate product, such as a story or a picture, which is then content analysed. The thematic apperception test (TAT), where the cue is usually a group of photographs illustrating the topic under investigation, has been much the most widely used form of construction technique in geographical studies, and especially so in the fields of hazard perception, for example in studies of flood risk perception (Kates, 1964; White, 1966) or drought risk perception (Saarinen, 1966), and landscape perception (Eastwood and Carter, 1981).

Even though relatively time consuming and, at times, difficult to content analyse quantitatively, TAT is nonetheless an extremely flexible technique which has an extremely wide range of potential applications. A specific N. Irish example illustrating the practical application of TAT in contemporary applied perceptual research will be examined in some detail in the concluding section of this paper.

3.- Completion Techniques - which present the subject with some type of incomplete product which he must complete in any manner that he wishes - have also been used in drought perception research, e.g. Barker and Burton (1969) used a cartoon of two farmers in a drought - stricken field and asked their subjects to complete the cartoon captions. However, completion techniques have proved in practice to be much more restrictive than TAT's in this type of research, and seem to have no significant practical advantage over construction techniques. Not surprisingly therefore there appear to be no contemporary examples of their use in geographical perception research.

4.- Choice, or Ordering Techniques - which require the respondent to choose from a number of alternatives the item or arrangement which fits some specified criterion - are probably the most commonly used techniques in geographical perception research. For example, Cox and Zannaras (1970) used a card-sorting technique to investigate cognitive maps and Metton (1969) a picture arrangement test to investigate street map and neighbourhood perceptions. Space restrictions here limit detailed examination of all the choice or ordering techniques available, but a more detailed look at two of the most commonly used of them will serve to illustrate both their range and their versatility.

4 a.- Semantic differentials.- shere sunjects are asked to describe some object by choosing on a scale between a provided list of polar opposite adjectives. Semantic differential testing is especially commonly used in landscape evaluation stuadies, where, although it lacks the minutely easier and more practical to uso in field based studies.

Figure 4 illustrates an example of the use of semantic differential testing in coastal landscape evaluation (in this case beach evaluation) on the Costa del Sol. In 
the case of this particular beach (Rincon de la Victoria) significant variation in beach perception is clearly evident at the national level.

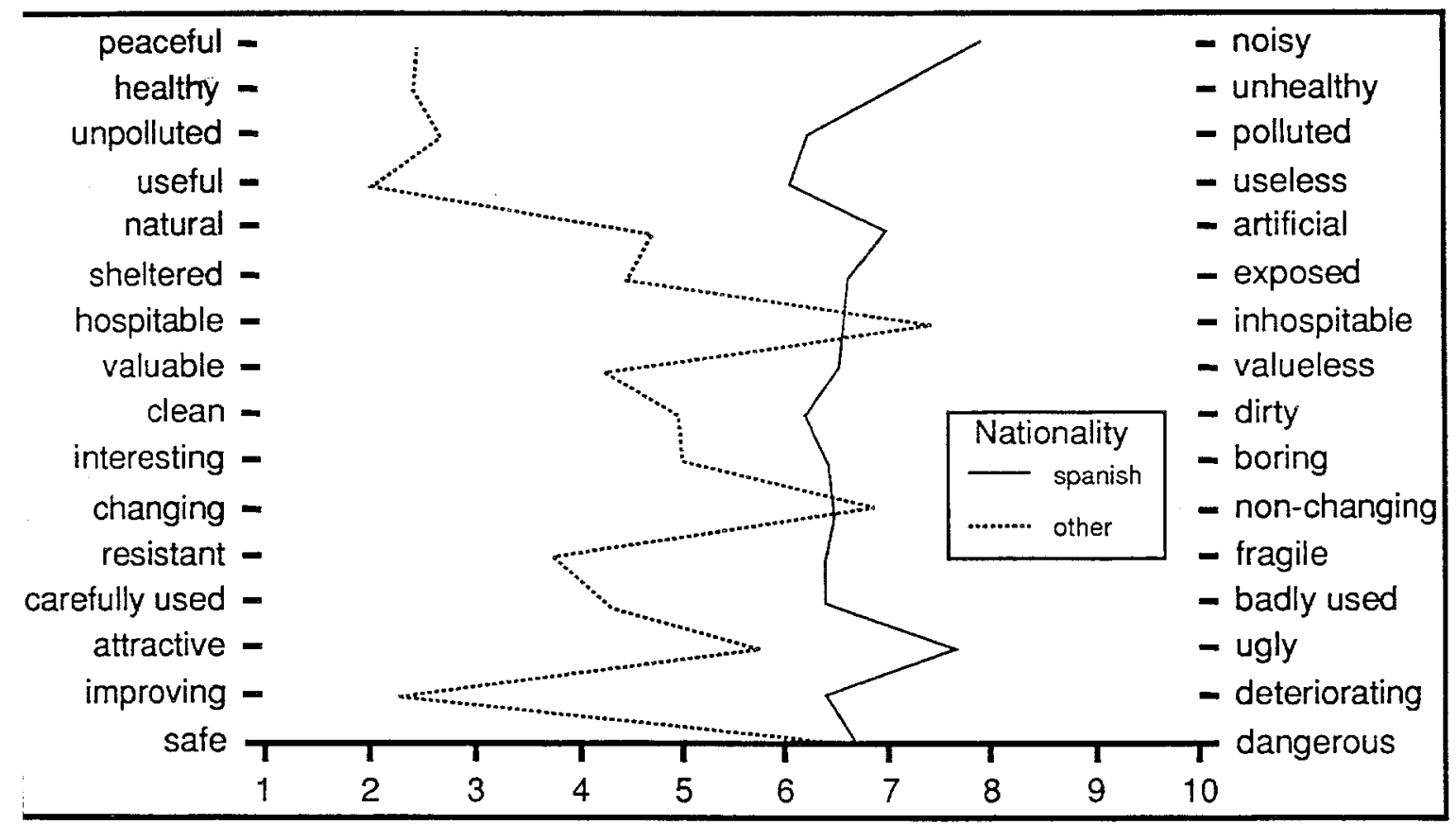

Figura 4.- Semantic Differental Testing. Costa del Sol Beach Perceptions

This example which is only a small part of a much larger on-going international coastal evaluation study provides an excellent example of the "insight, rather than total analysis" advantage of using perception researchparticularly in the early stages of an investigation. In this case the semantic differential test does not explain why, for example, in the case of this particular beach Spanish perceptions are so different from those of other nationalities, nor even what, if any, practical implications such differences might have (for example, for planning purposes) but it certainly provides specific and potentially interesting avenues for further detailed local investigations.

4 b.- Ranked or preferred choice - where subjects are presented with some simple cue, (for example a list or a pictorial representation) and asked to rank their 
preferences according to some designated criteria - as, for example, in the national stereotypes analysis previously described in Figure 1.

Ranked / preferred choice techniques have been especially widely used in the spatial preference / residential desirability research fields, for example by Gould (1966). Figure 5 illustrates a N. Irish example of a version of the technique being used in this same spatial preference context.

In this example, based on first year university geography practicals at the University of Ulster, the students were first given an outline map of the British isles divided into 23 regions (Fig. 5a) and then asked to rank the regions in terms of their perceived residential desirability, i.e. rank 1 -the region where they would most like to live; to rank 23- where they would least like to live. The following formula was then applied for each region:

(Times region is in ranks 1-3) - ( Times in ranks 21-23)

Number of students

This gives a potential score for each region ranging from +100 (the best: always preferred) to -100 (the worst: always hated).

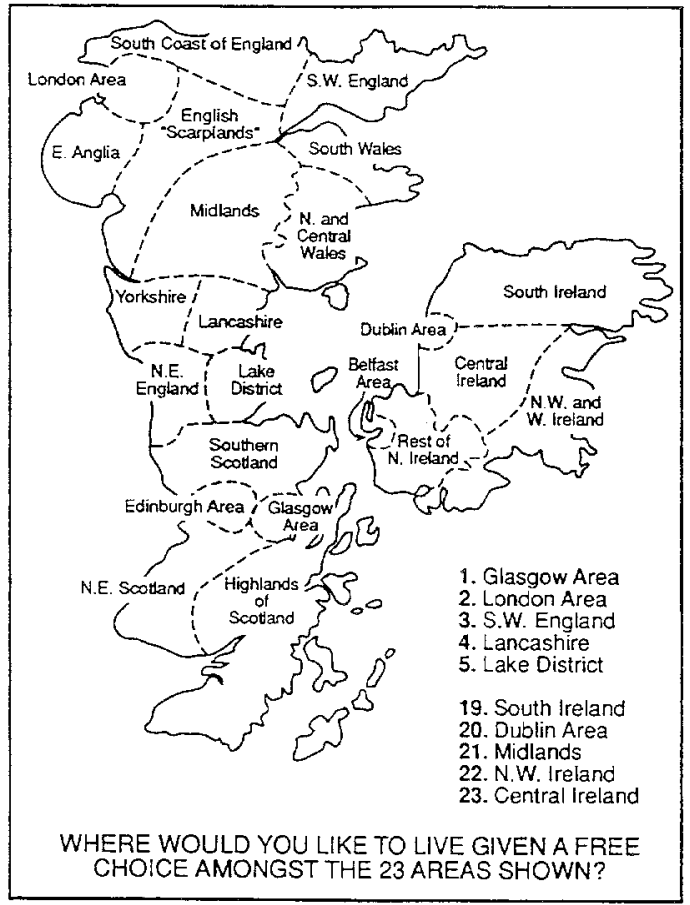

Figure 5a.- Regional Residential Desirability Practical 


\begin{tabular}{|c|c|c|c|c|c|c|c|c|}
\hline & 1973 & 1974 & 1975 & 1976 & 1977 & 1978 & 1979 & 1980 \\
\hline Belfast Area & -36 & -23 & 56 & -33 & -34 & -24 & -12 & -5 \\
\hline Rest of N. Ireland & +75 & +53 & +42 & +37 & +45 & +38 & +47 & +30 \\
\hline Dublin Area & +10 & -5 & -16 & +4 & -2 & -10 & -3 & +5 \\
\hline Central Ireland & -19 & -10 & +16 & 0 & 0 & 0 & -8 & -5 \\
\hline N.W. \& W Ireland & +2 & -2 & +34 & +12 & +2 & +17 & +12 & +20 \\
\hline S. Ireland & +22 & +32 & +43 & +14 & +32 & +34 & +21 & +20 \\
\hline London Area & -44 & -33 & -68 & -42 & -32 & -24 & -47 & -30 \\
\hline S. Coast England & +19 & +23 & +30 & +33 & +27 & +14 & +21 & +40 \\
\hline S.W. England & +51 & +47 & +50 & +33 & +25 & +24 & +47 & +15 \\
\hline E. Anglia & +17 & +22 & +4 & -2 & +14 & +7 & +9 & $\underline{0}$ \\
\hline English Scarplands & +3 & +13 & +5 & +10 & +4 & -7 & 0 & +5 \\
\hline Midlans & -32 & -37 & -32 & -12 & -11 & -24 & -24 & -5 \\
\hline S. Wales & -20 & -2 & -21 & -17 & -9 & -17 & -3 & -10 \\
\hline N.C. Wales & -2 & -10 & +1 & -6 & -2 & -7 & -9 & +20 \\
\hline Yorkshire & +7 & -2 & +3 & -4 & -7 & 0 & -3 & -20 \\
\hline Lancashire & -25 & -20 & -16 & 4 & +9 & -10 & -6 & -10 \\
\hline Lake District & +34 & +58 & +68 & +39 & +29 & +78 & +32 & +30 \\
\hline N.E. England & -11 & -15 & -26 & -27 & -18 & -24 & -24 & -30 \\
\hline S. Scotland & +15 & +8 & +9 & +8 & 0 & +3 & 0 & 0 \\
\hline Edinbrough Area & +17 & +5 & -5 & +8 & +4 & 0 & +3 & 0 \\
\hline Glasgow Area & -61 & -53 & -67 & -44 & -51 & -37 & -44 & -35 \\
\hline N.E. Scontlan & -3 & -5 & -7 & -2 & -9 & +3 & -3 & -10 \\
\hline Highlands Scotland & -5 & -7 & +7 & +15 & -7 & -20 & -30 & -25 \\
\hline $\mathrm{N}:$ & 59 & 60 & 76 & 52 & 44 & 29 & 34 & 20 \\
\hline
\end{tabular}

Figure 5b.- Residential Desirability Scores. U.K. \& Ireland Regions

It is clear from the results of this particular practical class over a number of successive years (fig. 5b) that the pattern of residential preference which emerges for students resident in Ireland is essentially a consistent one. For example, the Glasgow region is ranked as the worst every single year and most regions rank annually with either consistently + , or consistently - scores.

Of course, as already discussed with reference to the semantic differential results in Figure 4, these results do not explain the rationale underlying this consistent pattern, nor the implications of it ; but they (a) do highlight that constant patterns do exist and cannot therefore be ignored, and (b) do delimit interesting avenues for further detailed research. 
In this particular case some of the underlying rationale can easily be further explored, and a number of consistent variables isolated. For example, there is a consistent underlying religious variable, as can be seen in the scores recorded for Dublin and Belfast broken down for protestant and catholic students (fig. 5c). Dublin (The capital of a predominantly catholic country) scores consistently higher amongst the catholic, than amongst the protestant students, and vice versa for Belfast (predominantly protestant).

\begin{tabular}{|ccccccccc|}
\hline & 1972 & 1973 & 1974 & 1975 & 1976 & 1977 & 1978 & 1980 \\
\hline 1. Protestans & & & & & & & & \\
Belfast & -14 & -27 & -26 & -19 & -54 & -71 & +6 & 0 \\
Dublin & -18 & -20 & -5 & -16 & -31 & -60 & -18 & -9 \\
\hline 2. Catholics & & & & & & & & \\
Belfast & -75 & -55 & -53 & -52 & -60 & -100 & -56 & -22 \\
Dublin & +25 & +45 & +22 & +16 & +3 & +60 & +6 & +22 \\
\hline
\end{tabular}

Figure 5c.- Residential Desirablity: Religious Variable

\begin{tabular}{|lrrrrrrrr|}
\hline & 1972 & 1973 & 1974 & 1975 & 1976 & 1977 & 1978 & 1980 \\
\hline 1. Belfast Resident Students & +25 & +33 & +33 & +31 & +38 & +100 & +67 & +50 \\
2. Res. of N. Ireland Students & -40 & -47 & -25 & -46 & -56 & -100 & -46 & -56 \\
\hline
\end{tabular}

Figure 5d.- Residental Desirability: Belfast-Home Loyalty Variable

There is also an extremely strong and consistent "home loyalty" variable. This is easily discernable by comparing the scores given for the Belfast region between those students who actually lived in the Belfast region, as opposed to those living in the rest of Northern Ireland (fig. 5d). Even at the hight of the N. Ireland "troubles" in the mid 1970's, when car bombings were commonplace in Belfast, this home loyalty variable maintained Belfasts positive image amongst its residents.

Obviously variables, such as in this case the religious variable, are not always of major significance in all residential preference perceptionresearch, but others, such as the home loyalty variable do appear to have universal significance (fig. $5 \mathrm{e}$ ) the results obtained from conducting this same exercise amongst Malaga university geography students. 


\begin{tabular}{|lr|}
\hline Andalucia & $+90,0$ \\
Valencia & $+35,0$ \\
Canarias & $+22,5$ \\
Baleares & $+12,5$ \\
\hline Asturias & $+10,0$ \\
Aragón & $+5,0$ \\
Cantabria & $+5,0$ \\
Murcia & 0 \\
\hline Galicia & $-5,0$ \\
Navarra & $-7,5$ \\
Castilla-la Mancha & $-10,0$ \\
Madrid & $-12,5$ \\
\hline Castilla-Leon & $-15,0$ \\
Extremadura & $-20,0$ \\
Cataluña & $-42,5$ \\
Pais Vasco & $-67,5$ \\
\hline
\end{tabular}

Figure 5e.- Spanish Residential Desirability. Malagueño Student Perceptions

5.- Expressive Techniques - are rather like construction techniques, but typically place as much emphasis on the manner and style in which the product is created, as on the product itself. Mental mapping, where sketch maps are drawn from memory are a particularly common use of such expressive techniques in geography, as for example in Lynch's Image of the City (1960) work, or Saarinen's (1971) work on student views of the world.

Although often of no obvious practical value, occaisionaly the use of expressive techniques and of mental mapping can occaisionally be salutory - if only to show what students don't know - see for example the mental maps of South America (fig. 6) drawn by university geography students.

Perceptual images are undoubtedly of intrinsic interest in themselves, but all too often they may have only limited practical application. Nonetheless, perception research is not always only of intrinsic interest; used properly it can also have strong practical application, as will now be demonstrated. 


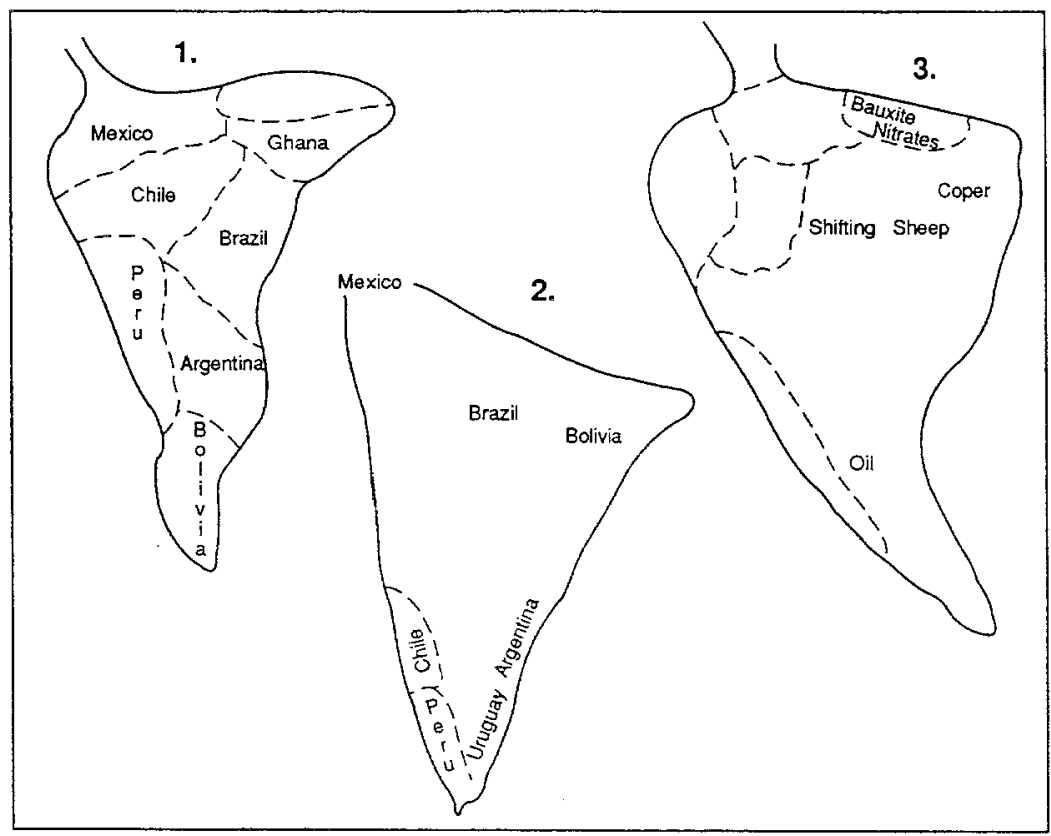

Figure 6.- Mental Maps of South America (countries and resources)

\section{THE PRACTICAL APPLICATIONS OF PERCEPTION RESEARCH}

It has been noted a number of times throughout this paper that perception studies can be a particularly useful and practical analytical tool in the early stages of a research project. However, the practical applications of perception research are certainly not restricted only to the formative research stage. They can also be used in support of, and in collaboration with, other more conventional data collection techniques throughout the duration of a given research project.

To illustrate this, I would like to briefly describe a research project in which I was involved last year on behalf of the N. Ireland Department of the Environment (Carter, Eastwood and Bradshaw 1992). This particular problem to be investigated centred around a traditional local $\mathrm{N}$. Ireland farming practice of taking beach sand and using it for a number of purposes around the farm which, because beach sand is no longer being replenished along the $N$. Irish coast, is presently causing the severe degradation, and even the total erosion of a number of $\mathrm{N}$. coast beaches. The problem,contracted to us by the N. Ireland Department of the Environment was therefore to asess the best way in which this sand removal could be checked, including if necessary the introduction of compulsory legislation to make the 
practice illegal, while at the same time minimising any potential local antagonism against perceived government infringement on traditional local rights.

This particular project is interesting in the context of this paper in that it involved all three of the broad research techniques elaborated in section"Indirect Self Report Techniques". Direct observation was necessary over a 9 month period on a sample of affected beaches to both assess the size of the problem and to identify "principal culprits". Direct self reports (questionnaires) were necessary to evaluate the current local perceptions of sand removal and progressive beach degradation and to guage general levels of local public support for possible compulsory restrictive legislation - which, not surprisingly, was much higher amongst the local non-farmers than amongst the farmers, almost all of whom were firmly against any prohibitive legislation.

However, the key question in this particular issue was not one of whether the farmers were against compulsory legislation, but rather the extent to which they would accept it if it was to be introduced. In the politically sensitive climate of $\mathrm{N}$. Ireland, there is an understandable reluctance on the part of government to introduce any new legislation which may be difficult to enforce because of undue local opposition.

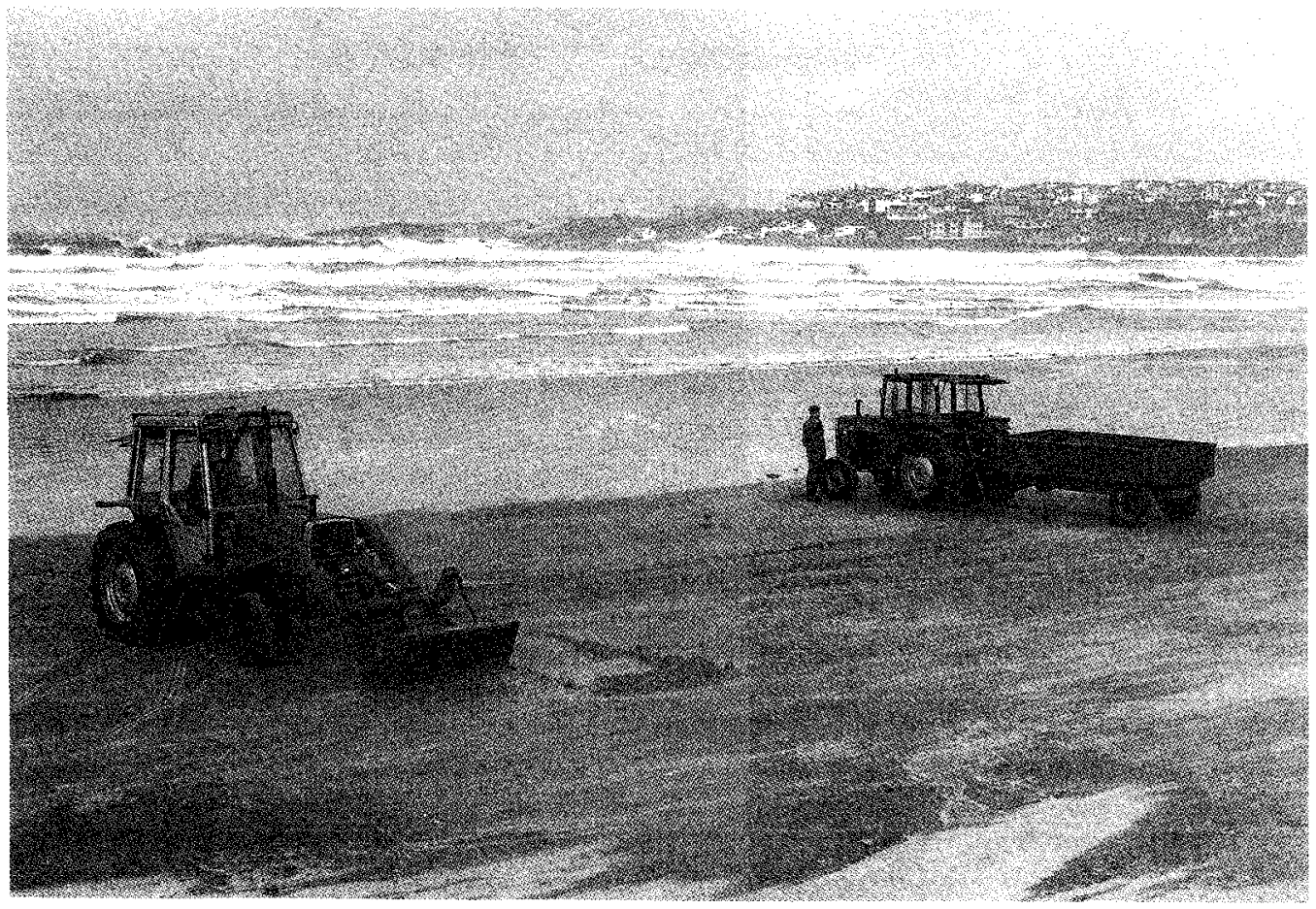

Figure 7a.- Sand Removal. Portstewart Beach 
However, in assessing this, direct questionnaire techniques proved to be a wholly unsatisfactory method for evaluating the potential strength of the farmers' hostility - the farmers not surprisingly being unwilling to answer directly whether or not, if legislation were to be introduced, they would actually be prepared to break the law. Consequently a more indirect approach was the only possible recourse - in this case TAT testing, using a suite of 4 cue photographs each portraying widely differing local beach conditions ( 2 of which are illustrated in figs. $7 \mathrm{a} / 7 \mathrm{~b}$ ).

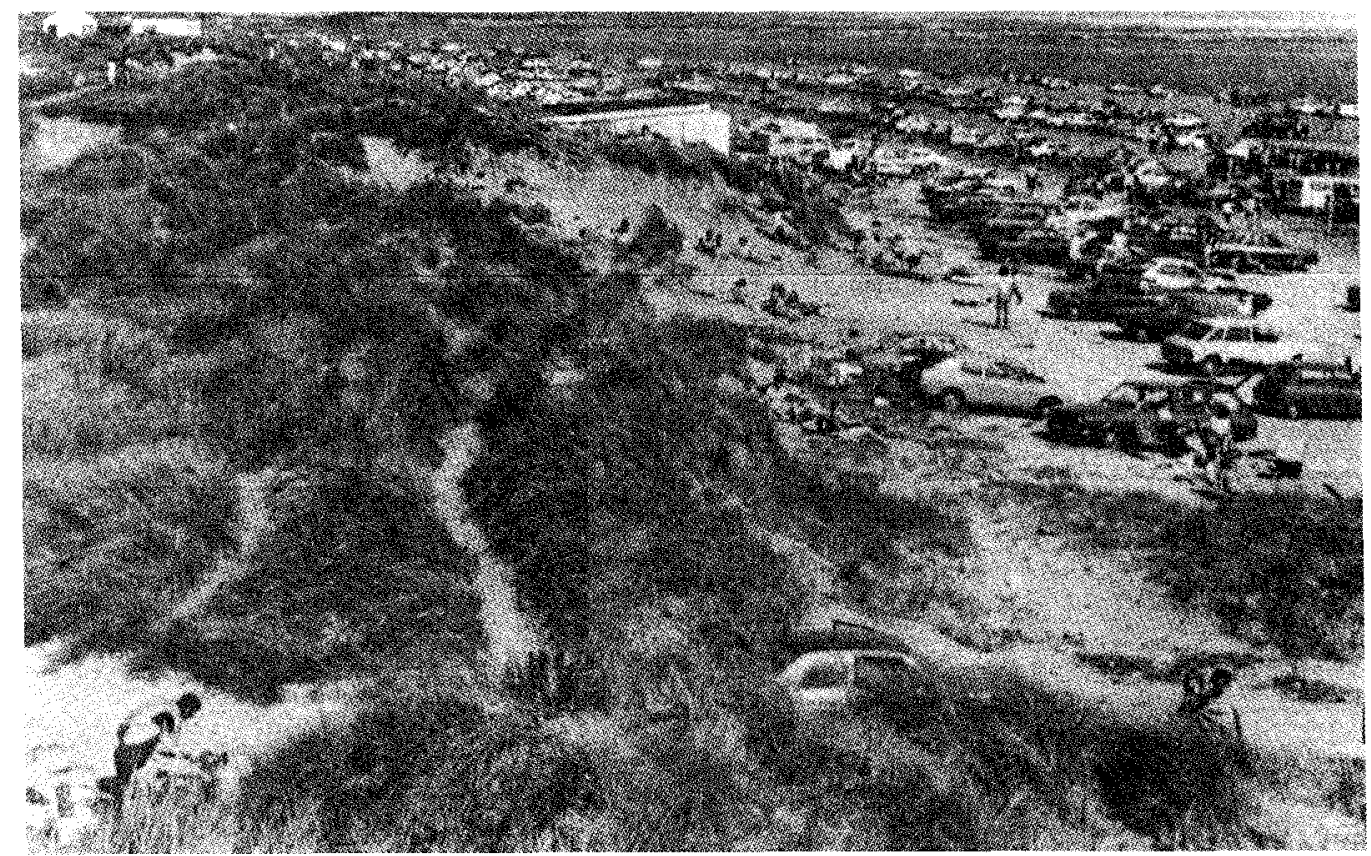

Figure 7b.- Tourism. Tyrella Beach

In the TAT's the perceptual responses of the farmers were directed towards:

1.- What was happening in each cue photograph?

2.- What had happened in the past to lead to this situation?

3.- What was likely to happen in the future?

Detailed content analysis of the farmers' responses to these cues resulted in a number of significant findings:

1.- that there was a well-defined, general environmental awareness amongst the farmers - hardly surprising given their profession - roughly evenly split between 'good' environmental images (clean beach, good weather etc.) and bad' environmental images (crowds, pollution, erosion etc.). 
2.- that the farmers had a strong majority perception of deteriorating beach conditions / environmental quality - i.e. they were aware of the problem.

3.- that they perceived this deterioration more as a consequence of tourist and natural pressures, than as a consequence of sand removal -e.g. of 46 causal images logged (e.g. tourist pressures including cars, natural erosion processes, pollution including oil, sewerage and rubbish etc.) only 6 referred to sand removal.

4.- that there was also a strong perception that beach deterioration did not represent permanent damage, that the beaches could be repaired and that the responsibility for these repairs lay with 'the authorities' - e.g. images of non-permanent damage (sand will come back, beach could be cleaned and repaired etc.) outscored those of permanent damage (beach beyond repair, nothing can be done etc.) on a 2:1 ratio.

The inescapable conclusion to de drawn from the TAT's was therefore that, although the farmers were aware of the beach degradation, they neither recognised the seriousness of it, nor recognised their own responsibility for it. Underlying these perceptions was a strong subconscious assumption that beach deterioration could not be serious because the public authorities would already have done something about it. Far from fighting legislation therefore the farmers would never believe in the seriousness of the current beach problem without legislation - but only if that legislation was accompanied at the same time by a comprehensive management plan which also tackled those other factors perceived by the farmers as being equally, or more responsible for the problem (tourism, sewerage etc.) - a conclusion now accepted and being acted on by the Department of the Environment, $N$. Ireland (Bradshaw, Carter and Eastwood, 1991).

In practical geographic and environmental research therefore, such as in this particular example, perception studies can not only be of contributory value as an initial and heuristic research tool, but also, at times, can be the only practical method for guaging the subconscious values and attitudes which may form the keys to human problems; thereby leading to more understanding decision making and to more sympathetic legislation and planning.

\section{BIBLIOGRAPHY}

BARKER, M. and BURTON, I. (1969): "Differential response to stress in natural and social environments: An application of modified a Rosenzweig picture frustration test", Natural Hazard Research Working Paper, 5, Univ. of Toronto.

BRADSHAW, P., CARTER, R.W.G. and EASTWOOD, D.A. (1991): Sand Removal From Beaches On The North Coast Of Northern Ireland, Univ. of Ulster, Coleraine.

CARTER, R.W.G., EASTWOOD, D.A. and BRADSHAW, P. (1992): "Small scale sediment removal from beaches in Northern Ireland : Environmental impact, community perception and conservation management", Aquatic Conservation, 2, pp. 95-113. 
COLE, J.P. (1970): "The Carioca's View of the World", Ideas in Geography, 26.

COX, K.R. and ZANNARAS, G. (1966): "Designative perceptions of macro-spaces: Concepts, a methodology and applications", Dept. of Geography working paper, , 17, Ohio State Univ.

CRAIK, K. H. (1970): "Environmental Psychology", in Craik et al. eds. New Directions in Psychology, New York.

EASTWOOD, D. A. and CARTER, R.W.G. (1981): "The Irish Dune Consumer : A Preliminary Investigation of Motivations and Perceptions of Coastal Recreation Visitors as a Potential Aid to Management Decision Making", J. of Leisure Research, vol. 14, 4, pp. 278-281.

EDWARDS, W. and TVERSKY, A. (1967):,Decision Making, London.

GOULD, P. (1966): "On mental maps", Michigan Inter-university Community of Mathematical Geographers Discussion Paper, 9, Univ, of Michigan,

HADDON, J. (1960): "A View of Foreign Lands", Geography, 65, 286-289.

KATES, R. W. (1964): "Hazard and Choice Perception in Flood Plain Management", Dept. of Geography Research Paper, 78, Univ. of Chicago.

LINDZEY, G. (1961): Projective Techniques in Cross-Cultural Research, New York.

LYNCH, K. (1960): The Image of the City, Cambridge, Mass.

METTON, A. (1969): "Le quartier: Etudes geographiques et psycho-sociologiques", Canadian Geographer, 13, pp. 299-316.

SAARINEN, T. F. (1976): Environmental Planning, Perception and Behavior, Boston.

SOMMER, R. (1969): Personal Space, New Jersey.

WHITE, G. F. (1964): "Choice of Adjustments to Floods", Dept. of Geography research paper, 93, Univ. of Chicago. 